\title{
Challenges Faced by ESL Teachers in Teaching English to the Students in Rural Schools: A Study Based on Five Rural Schools in the Kinniya Education Zone, Trincomalee, Sri Lanka
}

\author{
Abdul Halik, A.F ${ }^{1}$ \& Rifka Nusrath, G.M ${ }^{2}$ \\ ${ }^{1} \mathrm{~T} / \mathrm{Mu} / \mathrm{Al}-\mathrm{Hilal}$ Central College, Mutur, Trincomalee, Sri Lanka \\ ${ }^{2}$ DELT, Faculty of Arts and Culture, South Eastern University of Sri Lanka
}

DOI: 10.29322/IJSRP.10.11.2020.p10744

http://dx.doi.org/10.29322/IJSRP.10.11.2020.p10744

\begin{abstract}
Teaching English in rural schools has been a challenge for the most of the English as a Second Language and English as a Foreign Language teachers. Therefore, this study was carried out with the aim of investigating the challenges faced by the teachers in teaching English to the students in rural schools in the Kinniya Education Zone, Trincomalee. This study was a survey research, and both qualitative and quantitative methods were used for data collection. The research setting was five rural schools in the Kinniya Education Zone. 15 English teachers and 50 students from the selected schools were taken as sample population in this study. The data collection tools were questionnaire and interview. Based on the analysis of the data collection, the findings show that all the participants (15) encounter challenges in teaching English to the students in rural schools since many students show their dislike in learning English. Moreover, various factors such as poor parental support, lack of students' and parents' support, lack of learning/teaching materials at schools, both students' and parents' negative attitude towards learning English, lack of motivation and proper guidance, lack of interest in learning English, poor learning environment, poor family background and lower level of basic knowledge in English which contribute to the challenges faced by the teachers in teaching English at rural schools. These challenges and difficulties can be overcome when more focus is given to the students in primary stage to gain basic knowledge in English Language, several workshops, training programmes and motivational programmes about the importance of English are conducted for both parents and students and interest is created in learning English. Further, each and every school in rural setting should have possessed modern learning equipment like town schools and a language unit should be established with necessary equipment.
\end{abstract}

Index Terms: Challenges, English as a second language (ESL), Equipment, Kinniya Education Zone, Rural schools

\section{INTRODUCTION}

It is a well-known fact that English has been a universal language since it is spoken by many people as a first, second, or foreign language around the globe. In this sense, Dewi (2015) and Mydans (2007) state that English is used as a medium to interact with 
people from different cultures, ethnic, and social backgrounds in the world. As a result, the English Language is widely used as a common code by multilingual people around the globe. It is taught as a first language (L1), a second language (L2), or a foreign language (FL) in every country. On the other hand, teaching English as a second language or foreign language has been a challenge for most of the English as a Second Language (ESL) or English as a Foreign Language (EFL) teachers around the world. Alrawashdeh \& Al-zayed (2017) claims that teachers face different kinds of problems that make the process slow and rather weak. These problems put teachers into a dilemma in dealing with all the hardships in teaching students for the sake of their future. Similarly, English is taught as a second language in Sri Lanka since 1948. According to the educational curriculum of Sri Lanka, English is offered as the main subject in the school curriculum grades 1 to 13. As discussed above, several challenges and problems are faced by ESL teachers in teaching English. In particular, the teachers who perform their service at rural schools encounter several challenges and difficulties in their teaching process. Therefore, English Language Teaching seems to fail in rural schools. Many factors influence the failure such as the negative attitude of the students and parents in learning, poor learning environment, lack of sufficient learning/teaching materials, improper guidance and motivation, and insufficient qualified and trained teachers at rural schools. Students' negative attitude in learning has been one of the major challenges for most of the ESL teachers in teaching English. In a similar study, Juan (2006) claims that the learners' negative attitude toward English poses a great barrier for effective teaching. This negative attitude emanates from the fact that learners have limited competence in the language. Therefore, this current study was carried out to identify the challenges faced by ESL teachers in teaching English to the students in rural schools in Kinniya Education Zone, and the factors that contribute to the lower performance in English.

\subsection{Statement of the problem}

A universal fact accepted by the people that teaching English has been a challenge for ESL and EFL teachers in the countries where English is taught as a second or foreign language. Several research studies had been previously carried out investigating the challenges and difficulties faced by ESL/EFL teachers in teaching English. Similarly, In Sri Lanka, teaching English has been a challenge for most of the teachers. They encounter several difficulties in teaching English at schools and other educational institutions. As a result, English Language Teaching (ELT) seems to fail in Sri Lanka. Particularly, teaching English to students in rural schools is a major challenge for teachers. Likewise, Kinniya Education Zone is one of the education zones in Sri Lanka where $45 \%$ of the schools are located in rural settings. The ESL teachers who perform their teaching service at rural schools face several difficulties and challenges in their teaching process. Various factors contribute to the challenges and students' lower performance in English.

\subsection{Objectives of the Study}

- To identify the challenges faced by ESL teachers in teaching English to the students in rural schools of Kinniya Education Zone

- To identify the factors which affect teaching and learning English at rural schools in the Kinniya Education Zone

- To suggest some remedies and recommendations overcome the challenges faced by the ESL teachers in teaching English to the students in rural schools and to uplift their English education

\subsection{Hypotheses of the Study}


- English Language Teaching seems failure for most of the ESL teachers who perform their teaching service at rural schools

- Both parents' and students' negative attitude is one of the major factors to the challenges and students' lower performance in English

- Students do not show their interest in learning English like showing interest in other subjects.

\subsection{Limitations of the Study}

Kinniya Education Zone consists of three education divisions and 66 schools. Out of the 66 schools, 30 schools are located in rural. In all 30 rural schools, ESL teachers face challenges in teaching English to the students. However, to limit this study, 12 schools were randomly selected to carry out this research. There are over 25 ESL teachers at the selected 12 schools. Out of them, 15 teachers were selected to collect their opinions by questionnaire. Moreover, over 3500 students are studying at the selected schools. 50 students from the 12 schools were randomly selected to limit this study.

\subsection{Methodology}

\subsubsection{Research Design}

This study was conducted with the aim of investigating the challenges and problems faced by ESL teachers in teaching English for rural schools' students in Kinniya Education Zone. This study was a survey research, and both qualitative and quantitative methods were used for data collection. After the data collection procedure is over, the data were analyzed which was descriptive analysis.

\subsubsection{Sample}

The total population of this study focuses 3500 students and over 25 ESL teachers from 12 rural schools of the Kinniya Education Zone. The sample population of this study was 50 students and 12 ESL teachers.

\subsubsection{Research Instruments}

In this study, two research instruments were selected for data collection. They are questionnaire and interview. The first instrument was a questionnaire which consisted both close-ended and open ended questions. The questionnaire focused on collecting opinions among the ESL teachers regarding the challenges faced by the teachers in teaching English to the students at rural schools and factors which contribute to the challenges. The interview on the other hand was the second instrument which was used to collect opinions among the students regarding the interest in learning English, learning difficulties and factors which affect learning English.

\subsubsection{Data collection and analysis}

These instruments were used to collect both qualitative and quantitative data. The interview was used to qualitative data whereas the questionnaire was used to collect quantitative data. After the data collection is over, the data were analyzed statistically using graphs and tables which was descriptive analysis.

\section{RESEARCH ELABORATIONS}

Teaching English has been a significant problem among the ESL/EFL teachers around the world. Milon (2016) explains that the global distributions of English are often described in terms of three contexts such as English as a Native Language (ENL), English as 
a Second Language (ESL) and English as a Foreign Language (EFL). Therefore, in each country, English Language is taught based on the English curriculum but teaching English seems challengeable for most of the teachers. Several previous studies regarding the problems and challenges encountered by ESL/EFL learners in teaching English had been carried out. Therefore, according to the review of previous studies, drawing from a more recent study by Ngwaru \& Opoku-Amankwa (2010), it is arguable that learners who are socioeconomically disadvantaged face significant consequences in learning. This include absenteeism from school because of lack of school necessities, taking care of the sibling as parents look for food and even doing petty jobs to supplement on the family income. Adding to this is the minimal parental involvement in children's learning. According to their argument, poor parental attention is one of the factors which lead to the students' lower performance in education, particularly performance in English Language learning. With regard to teaching English, Endriyati (2019) asserts that teaching English as a foreign language is a challenging task both in rural and urban areas. Teachers have to pay attention to the language skills of the students such as reading, writing, listening, and speaking. He further emphasizes that besides that, the teachers should help the technology, and encourages the students to have enthusiasm, good attitude, and motivation to learn English.

Moreover, with regard to the importance of English, Rajasekaran \& Anburaj (2015) describe that importance of English today is something that can't be emphasized enough. It is as important as a graduation degree and knowledge of English can be something that stands between you and your dream. Despite, students in rural setting always fail to realize the value of English Language. They are not encouraged and they do not have sufficient facilities to learn English. Rajasekaran \& Anburaj (2015) further claim that there is a choice to learn English to everyone in cities but when the rural areas are concerned, they are let alone. According to Rajasekaran \& Anburaj (2015), cities have many institutions to learn English whereas rural areas do not have a scope of one institution. Therefore, the hospitability of the villages discourages the educators. Likewise there are many factors which contribute to the challenge and difficulties to teach English as well as to learn English. In this sense, according to Arroji (2016), he states some reasons for facing challenges to teach English for rural school students. They are; lack of clear-cut policy, lack of competent teachers, lack of understanding of aim, lack of exposure to the language, lack of suitable teaching aids and materials, lack of motivation and large Classes. Likewise, in the current study also, there are many factors which lead to failure of English Language Teaching (ELT) in rural settings. Moreover, a similar study had been carried out regarding the challenges in teaching English at both rural and urban schools. In this study, Endriyat et al (2019) conclude that there are some different challenges in teaching English at rural and urban schools. In rural schools, there are some challenges such as low motivation, the parents support, and lack of vocabulary. They further recommend that to overcome the problems of teaching English to the students in rural schools, the teachers should try to apply some methods in learning process, and make a good communication with the parents.

\section{FINDINGS}

This part concerns the findings of the data analysis. As far as the collection in concerned, the relevant data were collected using both questionnaire and interview based on the problem and hypotheses of this study. Accordingly, based on the analysis of data, the findings of the questionnaire show that a question was asked whether teaching English to the students in rural background is challengeable for ESL teachers, to which all 15 participants responded 'yes' on the other hand nobody responded 'yes'. This has been the problem for most of the teachers in rural schools. Various factors contribute to the challenges faced by the teachers in teaching English at rural schools. They are: lack of students' support, students' negative attitude in learning, poverty, poor parental attention, lack of learning equipment and more. Moreover, the participants were asked whether their students are interested in learning English, to which 10 of the participants responded 'no' whereas 5 of the participants responded 'yes'. Although most of the students have lack 
of interest in learning English, some of the students are interested in learning English. If they are concerned, they are interested in learning all the subjects including English Language. Similarly, the participants were asked whether their students are supportive and attentive in their teaching process in the classroom, to which 9 of the participants responded 'no' and 6 of the participants responded 'yes'. This is one of the important factors for finding challenges in teaching. When the students shows negative attitude, indeed, teaching and learning process will be failure. In the next question, the participants were asked whether their school consist of enough teaching and learning equipment and facilities, to which 12 of the participants responded 'no' whereas 3 of the participants responded 'no'. Due to lack of learning teaching equipment, both teachers and students face challenges in teaching and learning English. Always modern equipment like computers, multimedia, audio recorder etc. create an interest to the students and they make the students attentive.

Moreover, a question was asked with regard to attendance and participation in the classroom. The participants were asked whether the students attend school regularly, to which 10 participants responded 'yes' and 5 participants responded 'no'. Students' lack of participation is one of the factors which leads to face challenges in teaching English to the students. The next question was regarding parental support and interest in which the participants were asked whether the parents are interested in educating their children and are supportive for their learning. 9 of the participants responded 'no' while 6 of the participants responded 'yes'. Based on the findings regarding parents' support and interest, most of the parents in rural background were not supportive and interest in educating their children. The following table shows participants' response ( \% ) to the questions.

\begin{tabular}{|c|c|c|c|}
\hline \multirow[t]{2}{*}{ No } & \multirow[t]{2}{*}{ Questions in the questionnaire } & \multicolumn{2}{|c|}{$\begin{array}{l}\text { Participants' percentage (\%) for } \\
\text { response }\end{array}$} \\
\hline & & Yes & No \\
\hline 01 & $\begin{array}{l}\text { Do you think that teaching English to the students in rural } \\
\text { background is challengeable? }\end{array}$ & $100 \%$ & - \\
\hline 02 & Are your students interested in learning English? & $34 \%$ & $66 \%$ \\
\hline 03 & $\begin{array}{l}\text { Do you think that your students are supportive and attentive in } \\
\text { your teaching process in the classroom? }\end{array}$ & $40 \%$ & $60 \%$ \\
\hline 04 & $\begin{array}{l}\text { Does your school consist of enough teaching and learning } \\
\text { equipment and facilities? }\end{array}$ & $20 \%$ & $80 \%$ \\
\hline 05 & Do your students attend school regularly? & $36 \%$ & $66 \%$ \\
\hline 06 & $\begin{array}{l}\text { Do you think that their parents are interested in educating their } \\
\text { children and are supportive for their learning? }\end{array}$ & $40 \%$ & $60 \%$ \\
\hline
\end{tabular}

Table 1 (Participants' percentage for response to the questions)

Further, with regard to the factors which contribute to the challenges in teaching and learning English in rural setting, both students and teachers were asked about the factors through questionnaire and interview. The question was open-ended. Therefore, the 
participants had given various factors which affect teaching and learning English in rural setting. Based on the response of the participants, the following table shows the findings.

\begin{tabular}{|l|c|l|c|}
\hline $\begin{array}{l}\text { Factors affecting teaching English } \\
\text { based on teachers' response }\end{array}$ & $\begin{array}{l}\text { Number of } \\
\text { participants }\end{array}$ & $\begin{array}{l}\text { Factors affecting learning English } \\
\text { based on students' response }\end{array}$ & $\begin{array}{l}\text { Number of } \\
\text { participants }\end{array}$ \\
\hline $\begin{array}{l}\text { Lack of students' and parents' } \\
\text { support }\end{array}$ & 12 & $\begin{array}{l}\text { Lack of motivation and proper } \\
\text { guidance about learning English }\end{array}$ & 32 \\
\hline $\begin{array}{l}\text { Students' negative attitude towards } \\
\text { learning }\end{array}$ & 13 & $\begin{array}{l}\text { Giving more importance to other } \\
\text { subjects than English }\end{array}$ & 38 \\
\hline $\begin{array}{l}\text { Lack of interest in learning English } \\
\text { guidance towards about learning } \\
\text { English }\end{array}$ & 11 & Lack of interest in learning English & 34 \\
\hline $\begin{array}{l}\text { Environment and poor family } \\
\text { background motivation and proper }\end{array}$ & 13 & Low level of basic knowledge in \\
English Language & 37 \\
\hline $\begin{array}{l}\text { Lack of sufficient learning/teaching } \\
\text { materials at school }\end{array}$ & 12 & Lack of learning environment & 37 \\
\hline
\end{tabular}

Table 2 (Factors affecting teaching and learning English in rural setting)

\section{CONCLUSION}

Teaching English at rural school has been a challenge for a large number of ESL teachers in Sri Lanka. Similarly, the ESL teachers at rural schools in the Kinniya Education Zone, Trincomalee encounter a number of difficulties and challenges in teaching English. Therefore, this study was carried out with the aim of investigating the challenges faced by ESL teachers in teaching English to the students in rural schools. According to the findings of the data collection, this study can be concluded that all the participants (15) encounter challenges in teaching English to the students in rural schools since a large number of students are not interested in learning English. Moreover, the findings show that various factors which contribute to the challenges faced by the teachers in teaching English at rural schools. They are: poor parental support, lack of students' and parents' support, lack of learning/teaching materials at schools, both students' and parents' negative attitude towards learning, lack of motivation and proper guidance, lack of interest in learning English, poor learning environment, poor family background and low level of basic knowledge in English.

These challenges and difficulties can be overcome when the followings are implemented at rural schools in the Kinniya Education Zone. They are as follow: 
- More focus should be given to the students in primary stage to gain basic knowledge in English Language.

- A number of workshops, training programmes and motivational programmes about the importance of English should be conducted for both parents and students and teachers should create an interest in learning English.

- Each and every school in rural setting should have modern learning equipment like town schools and a language unit should be established with necessary equipment. The principal, Old Boys Association (OBA) and School Development Society (SDC) should take steps to collect funds from outsiders to establish the unit.

\section{APPENDICES}

\section{Appendix A: Questionnaire}

This questionnaire has been designed to collect the relevant information about the challenges and difficulties faced by the ESL teachers in teaching English to the students in rural schools for carrying out a research. Therefore, kindly and complete this questionnaire and provide your support to achieve the aim of this study. The information will be strictly treated confidential

Select the suitable answer according to your point of view and underline.

Name

Current School

1. Which section are you teaching to?

- Primary section

- Junior Secondary section

- Senior Secondary section (A/Level)

2. Do you think that teaching English to the students in rural background is challengeable?

- Yes

- No

3. Are your students interested in learning English?

- Yes

- No

4. Do you think that your students are supportive in your teaching process?

- Yes

- $\quad$ No

5. Does your school consist of enough teaching and learning equipment and facilities?

- Yes

- No

6. Do your students attend school regularly?

- Yes

- No 
7. Do you think that their parents are interested in educating their children and are supportive for their learning?

- Yes

- $\quad$ No

8. What are the challenges and difficulties do you face in teaching English to the students in rural schools?

Appendix B: Interview

Followings are the interview questions given to the students.

1. What is your name?

2. Where do you come from?

3. Which school are you studying?

4. Which class are you in?

5. What is your father doing?

6. Are you interested to learn English?

7. Do you study English at home?

8. Do you go for English private classes?

9. Why do you show lower performance in English than other subjects?

10. How can you improve your English?

\section{ACKNOWLEDGEMENT}

First of all, we would like to thank Almighty Allah for giving this opportunity to publish our research article in the International Journal of Scientific and Research Publications (IJSRP). Further, on this pleasant moment, we are so glad to thank our parents and spouse for their continuous positive motivation and guidance for doing this research.

Moreover, we are glad to express our heartfelt thanks to the ESL teachers and students in Kinniya Education Zone, Trincomalee for their support for data collection.

\section{REFERENCES}

Arroji, S (2016). Challenges of Teaching English Language in the Rural Context, Paripex - Indian Journal of Research, Vol: 5(3).

Alrawashdeh, A. I \& Al-Zayed, N. N. (2017). Difficulties That English Teachers Encounter while Teaching Listening Comprehension and Their Attitudes towards Them, English Language Teaching, Canadian Center of Science and Education, Vol. 10(5).

Dewi, A. (2015). Perception of English: a study of staff and students at universities in Yogyakarta, Indonesia. Cambridge Scholars Publishing.

Endriyati et al (2019). Challenges In Teaching English At Rural And Urban Schools And Their Solutions, International Journal of Scientific \& Technology Research, Vol: 8(10).

Milon, R. K. (2016). Challenges of Teaching English at the Rural Primary Schools in Bangladesh: Some Recommendations, Asia Pacific Journal of Social Sciences, Vol: 2(3). 
Mydans, S. (2007). Across cultures, English is the word. The New York Times. Retrieved from http://www.nytimes.com/2007/04/09/world/asia/09iht-englede.1.5198685.html? r=0.

Ngwaru, J. M. \& Opoku-Amankwa, K. (2010). Home and school literacy practices in Africa: listening to inner voices, Lang. Educ, Vol: 24, pp. 295-307.

Rajasekaran, W. C \& Anburaj, G (2015). Ways of Teaching English in Rural Areas. Journal of Humanities and Social Science (IOSRJHSS). Vol: 20(2), pp. 100-102.

Usó, J. E. (2006). Current Trends in the Development and Teaching of the Four Language Skills. Berlin, New York: M. de Gruyter.

\section{AUTHORS}

First author - Abdul Halik, A.F. PhD (r), MA in Linguistics, BA in English, BBA, HND in English. NAITA, T/Mu/Al-Hilal Central College, Mutur, Sri Lanka. abdhulhalik@gmail.com

Second author - Rifka Nusrath, G.M. MA in Linguistics, BA in English, HND in English. DELT, Faculty of Arts and Culture, South Eastern University of Sri Lanka. rifkanusrath@gmail.com / rifkanusrath.seu.ac.lk 